\title{
THE WEIGHTBEARING SHOULDER
}

\author{
By P. C. Wing, M.B., M.Sc., F.R.C.S.(C) and S. J. Tredwell, M.D., \\ F.R.C.S.(C). \\ Shaughnessy Hospital Pavilion, G625 Department of Surgery, 4500 Oak Street, \\ Vancouver, B.C., Canada V6H 3 NI.
}

Key words: Paraplegia; Crutch-walking gait; Shoulder degeneration; Bone density; Acromio-humeral interval.

Summary. To determine the effect of the swing-through crutch-walking gait on shoulder degeneration, 20 shoulders were examined in ten patients who had used the swing-through gait for a mean of 8.7 years. No degenerative changes were found in the 20 examined shoulders either clinically or radiographically. A special X-ray view was determined to assess potential degenerative changes. The patients showed a mean increase in the forearm bone density as a result of their crutch-walking gait.

\section{Introduction}

THE swing-through crutch-walking gait is the fastest way of walking with crutches, (Friedland, I968; Shoup, Fletcher \& Merrill, 1974) and as such demands a high rate of energy expenditure. It is usually a temporary step en route to a more stable and comfortable gait when strength and mobility is improved with the aid of prosthesis or orthosis, or by recovery from extremity injury. For a few patients it is their final level of ambulation, either because of a neurological deficit permitting no independent lower limb motion or because of difficulty with prosthetic limb fitting. Little work has been done on the biomechanics or possible side-effects of crutch utilisation. Shoup et al. (1974), listing the literature regarding crutch locomotion, performed a biomechanical study of the crutch-walking gait, and concluded that the crutch could be modified to collapse slightly and thus absorb energy as the crutch load was increased, to release it later in the cycle of the crutch-walking gait. It was felt that unusual stress on the upper limb might produce structural or physiological changes, particularly in the shoulder joint, an unstable joint not habitually used in homo sapiens to withstand vertical thrust.

\section{Subjects and Methods}

Many sources were approached to locate a series of swing-through crutchwalking subjects: mostly effectively functioning, independent citizens. The majority of them had, at some time, attended the G.F. Strong Rehabilitation Centre in Vancouver. A series of ten subjects, selected by gait and availability, were evaluated, all having used a swing-through gait for a minimum period of approximately two years. Diagnoses included six patients with complete or partial paraplegia affecting L I or higher levels, two with old poliomyelitis, one with myelomeningocele, and one with cerebral palsy. There were seven males, three females. 
The historical information required included age, weight, nature of the lesion, times for which the patients had been crutch-walking, the type of crutch used and the approximate total daily distance covered. The nature of any shoulder symptoms was elicited as well as distal upper limb complaints. Examination of the shoulder was performed in the standard manner described by the American Orthopaedic Association with documentation of the range of motion in all planes (American Orthopaedic Association, 1972). Neurological function of the upper limbs was also recorded in detail.

A single X-ray view was devised (Figs I \& 2). This was a projection

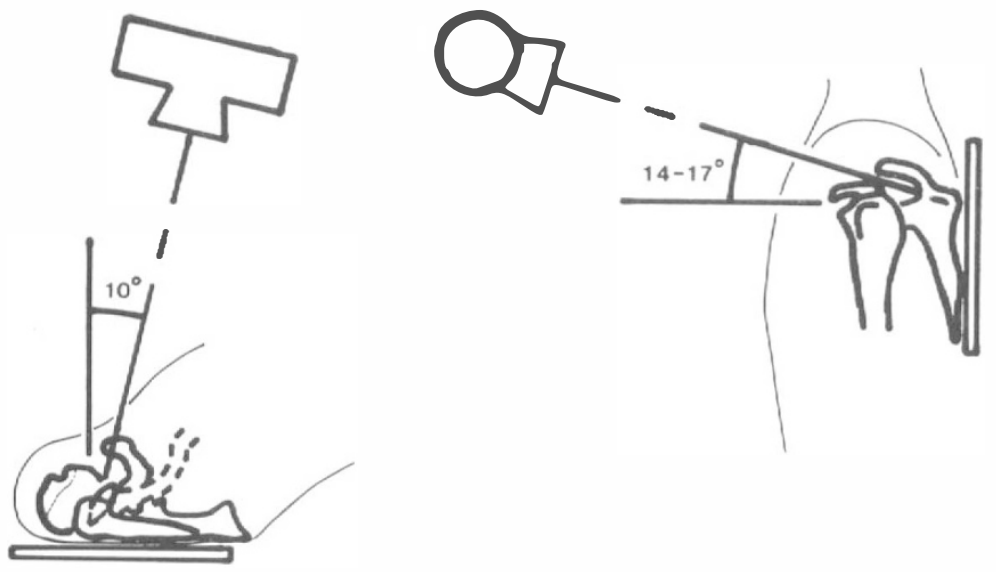

FIG. I

The Ideal A-P view of the shoulder.

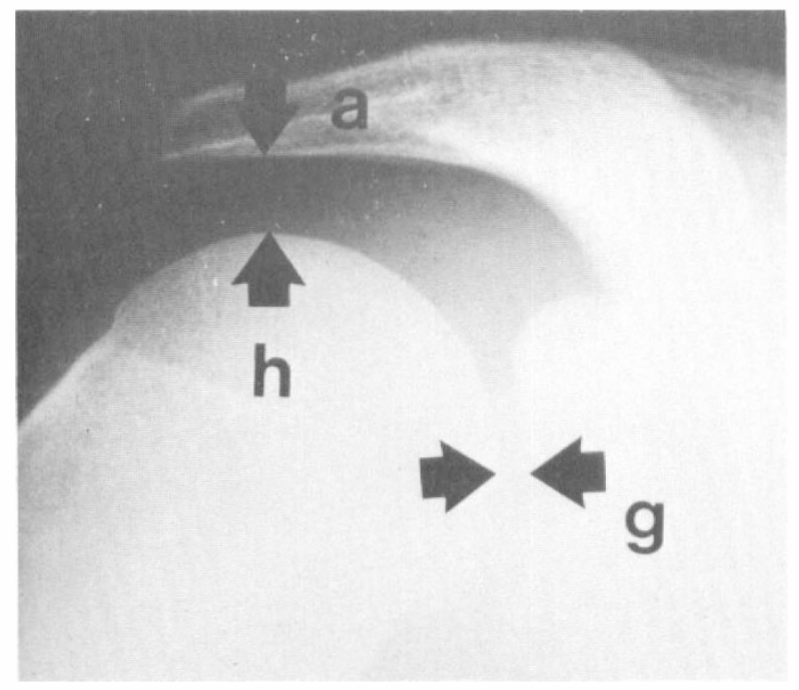

FIG. 2

Movement of acromio-humeral and gleno-humeral intervals from the ideal antero-posterior view. 
taken with the patient standing with the beam directed $10^{\circ}$ laterally and I4 $-17^{\circ}$ caudad, the scapula in the plane of the cassette. It showed in profile both the acromioclavicular and glenohumeral articulation. Both shoulders were examined, at rest and bearing the subject's full weight. Each roentgenogram was examined in detail and numerical data concerning joint space and any changes on weightbearing recorded. The relative optical density of the humeral head to its adjacent soft tissues was also recorded, using a Kipp \& Zonen Optical Densitometer.

To evaluate the degree of stress being borne by the upper limb, photon beam absorptiometry was performed of the left radius one-third of its length from the wrist, using a Norland-Cameron machine with a point source of iodine 125 (Boyd et al., r974).

A control group of four subjects with asymptomatic shoulders were similarly evaluated.

\section{Results}

The age range of this group of patients was from 19 to 30 years (mean 23.7). Weight range was $55-89 \mathrm{~kg}$ (mean $68.8 \mathrm{~kg}$ ). Crutch-walking gait had been used from 20 months to I9 years (mean 8.7 years).

All had used elbow crutches by preference but six of the subjects had experienced difficulty with this type of crutch. Two had broken in use with one patient returning to underarm crutches, while four complained that the elbow grip was inadequately made, tending to gape and become patulous with age, with securing screws loosening, pinching the skin or later breaking out.

There were two groups of subjects distinguishable on the basis of activity: six walking about 3-5 blocks per day, four with greater mobility covering a distance of I 5-25 blocks per day.

Most patients had had some complaint related to their upper limb. In two this was related to the accident (cervical pain in one, a humeral neck fracture in another). Two more occasionally noted some soreness in hands and wrists, one only after covering long distances. Two female patients had occasional neck and shoulder aching, apparently related to postural or occupational causes. Two male patients had an exertional ache after a considerable distance (one only on ascending several flights of stairs). Two had had symptoms at an earlier age, one with pain in both shoulders at age I3 which subsided spontaneously without an identifiable radiological abnormality. The other had required steroid injections into one shoulder for pain two years previously, but this was the only subject to seek medical attention for shoulder symptoms.

No evidence was found of any clinical or radiological degeneration. One post-poliomyelitis patient had a slightly reduced range of motion in one shoulder, and the patient with previous surgical neck fracture had slight limitation of internal rotation. No neurological deficit was attributable to the use of the crutch, with special consideration for function of the brachial plexus, ulnar nerve at the elbow, and the median nerve in the hand.

Radiological measurements were made of the gleno-humeral and acromio-humeral joint spaces of each shoulder, both loaded and unloaded. The mean acromio-humeral interval was $9 \mathrm{~mm}$. The figures obtained on loading were identical: this was also true of the control group. 


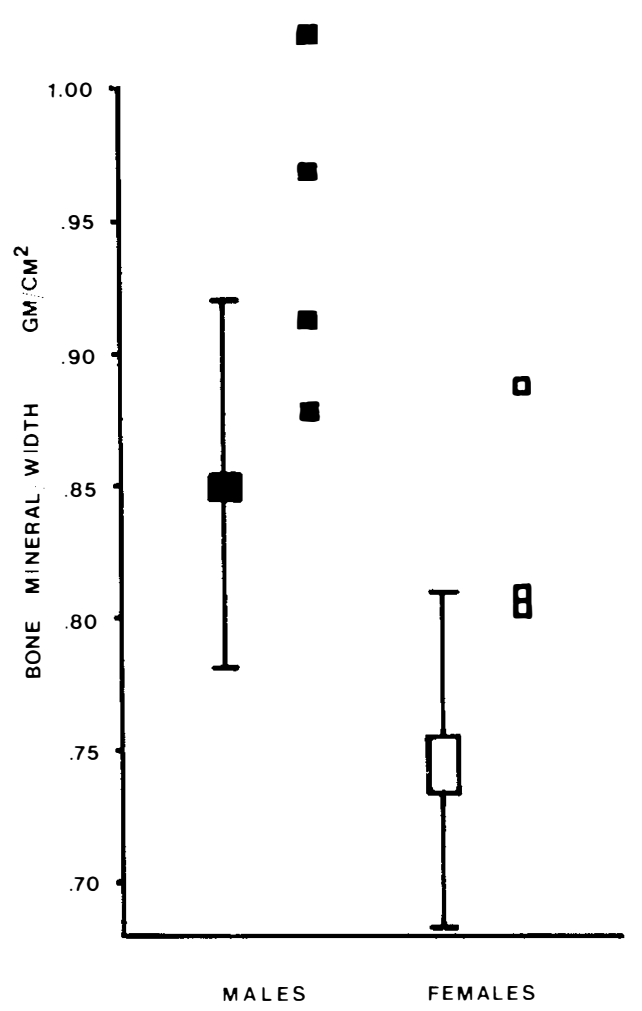

FIG. 3

Bone mineral content of crutchwalkers in relation to mean and range for normal subjects.

Photon beam densitometry was used to assess the degree of stress that the subjects were applying to the upper limb: the results are demonstrated in Fig. 3. The normal mean and range for sexes is shown, and the crutch-walkers are demonstrated to be at the high end of normal or greater with regard to bone density. Videodensitometric values, expressed as a relative optical density between the humeral head and adjacent soft tissues, correlated inversely with body weight rather than with photon beam densitometry, and it was not felt to be a helpful method in this situation.

Some non-quantifiable observations were made on the gait of style of these subjects. In all, the acromion and scapula were seen to rotate anteriorly over the humeral head during the stance phase of the upper limbs, the shoulders rising over the upper limbs in a manner taught by physiotherapists. This was seen as an 'acromial roll' over the humeral head. In some patients this would manifest itself on loading as the 'coracoid dip' on the weightbearing X-ray. It was felt that this manoeuvre would tend to unload the tendinous and ligamentous structures of the shoulder and increase the force vector acting through the acromion and glenoid.

\section{Discussion}

In a study of Ioo spinal cord injured patients and Ioo normals, Griffiths 


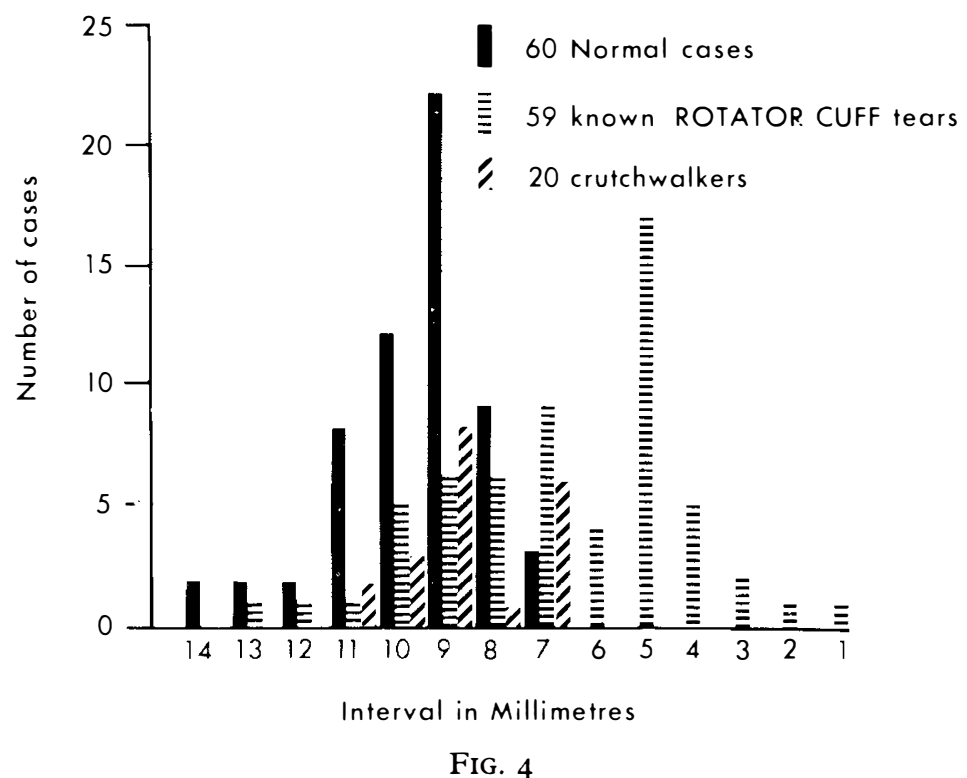

Acromio-humeral interval of crutchwalkers compared with normal and rotator-cuff-torn populations (after Wiener and MacNab (I970)).

and Zimmerman found no difference in radial bone mineral content between the two groups (Griffiths \& Zimmerman, 1973). This group of crutchwalkers demonstrates significantly elevated values. This is undoubtedly because these people are placing a lot of stress on their upper extremities. There is, however, no deviation from a normal mean value for acromiohumeral distance. This was recorded for 60 normals and 59 shoulders with known rotator cuff tears by Wiener and MacNab in I970, as demonstrated in Fig. 4, with the distance in the crutch-walkers shoulders added. There was no difference between the loaded and unloaded shoulders of the crutch-walking group. Gleno-humeral joint space did not differ from the control group in this series.

The structures that bear weight are the acromion, coraco-acromial ligament and the coracoid process. The length of the acromion and the coverage provided by it to the humeral head varied considerably, yet no lateral subluxation of the head was seen. The rotator cuff must provide a major stabilising force and transfer some of the load in a medial vector via the glenoid. On weightbearing the acromion may rise over and provide increased coverage for the humeral head which can deepen the socket of this otherwise shallow joint and again increase the glenoid load.

These relatively young adults had however strained their shoulders in a most punishing manner for from almost 2 to 19 years. Contrary to Brewer's statement (Brewer, I979) that ageing of the tendon of the rotator cuff is accelerated by the forces of demand on the musculotendinous unit, it seems that these patients have shown no untoward effect. Wright and Haq (Wright \& Haq, I976) have also suggested that chronic trauma can play a causal role in shoulder periarthritis. It may be that Uhthoff's cellmediated cartilaginous metaplasia seen in rotator cuff degeneration 
(Uhthoff, I974) results from a sustained negative pressure on the joint, and that the intermittent loading of the crutch-walking paraplegic may provide a positive pressure and be an ideal way to provide synovial nutrition of the cuff and hence preserve the acromio-humeral joint space. Biomechanically, a major factor in favour of the shoulder's durability is the fact that on a swing-through crutch-walking gait little more than half the body weight would be transmitted through the shoulder, as opposed to the $2 \frac{1}{2}-3$ times body weight that passes across the hip joint in stance phase. Moreover, the daily activity levels and total mileage covered are unlikely to equal those of these patient's bipedal peers.

A long-term follow-up of these patients would obviously be helpful, but medical care has not in the past provided a great life expectancy for these patients. One patient was examined, who was aged 85 years and had poliomyelitis in infancy, he had required a swing-through gait because of a flail lower limb. His shoulders had been intermittently painful for only the previous I-2 years and stiff for the previous 6 months. With no localized tenderness this patient exhibited a painful arc from $60^{\circ}$ to peak elevation at $105^{\circ}$, and a late stage carpal tunnel syndrome affected the dominant right hand but did not prevent activities, even when embroidering.

\section{Conclusions}

In this series of ten patients, using a swing-through gait as their primary form of locomotion the effect of increased loading was demonstrated by increased radial bone mass. With a mean time on crutches of 8.7 years, no degenerative changes were evident clinically or radiographically in the 20 examined shoulders. A few subjects complained of occasional fatigue symptoms in the shoulder.

In the weightbearing shoulder, the acromion tends to roll over the extending humeral head, but joint congruence and relative positions of the humeral head and scapula were unchanged from the normal.

\section{RÉSUMÉ}

En vue de déterminer les effets de l'utilisation de cannes lors de la marche en pendulaire, nous avons examiné les vingt (20) épaules de dix (10) patients qui avaient marché de cette manière durant 8.7 années en moyenne.

Nous n'avons pas noté de dégénérescence dans les vingt épaules examinées, ni sur le plan clinique, ni sur le plan radiologique. Nous avons mis au point un angle spécial pour prendre les radiographies qui nous permet de détecter d'éventuelles altérations osseuses. Les patients ont présenté une forte augmentation de la densité des os de l'avant-bras comme résultat de leur marche en pendulaire.

\section{ZUSAMMENFASSUNG}

Bei Io Patienten, die durchschnittlich 8, 7 Jahre den Durchschwunggang benutzen, wurden die Schultergelenke (20 Gelenke) untersucht. Ziel war die Erkennung degenerativer Schäden als Folge des Langzeitgebrauches von Unterarmgehstützen beim Durchschwunggang. Weder klinisch noch röntgenologisch waren irgendwelche Schäden nachweisbar, obwohl spezielle Röntgenuntersuchungsverfahren zum Nachweis solcher Schäden angewendet wurden. Alle Pattienten zeigten eine gesteigerte Knochendichtigkeit der Unterarmknochen als Folge des Gehens mit Unterarmgehstützen. 


\section{REFERENCES}

American Orthopaedic Association. (I972). Manual of Orthopaedic Surgery. A.O.A.

Boyd, R. M., Cameron, E. C., McIntosh, H. W. \& Walker, V. R. (I974). Measurement of bone mineral content in vivo using photon absorptiometry. C.M.A.F., III, I20II 205 .

Brewer, B. J. (1979). Ageing of the rotator cuff. Amer. F. Sports Med., 7, I02-1 Io.

FrIEDLAND, F. (1968). Rehabilitation in spinal cord injuries. In: S. Licht (ed.), Rehabilitation and Medicine. Elizabeth Licht, New Haven.

GRIFfithS, H. J. \& ZimmERmAN, R. E. (I973). The use of photon densitometry to evaluate bone mineral in a group of patients with spinal cord injury. Paraplegia, I0, 279-284.

Shoup, I. E., Fletcher, L. S. \& Merrill, B. R. (I974). Biomechanics of crutch locomotion. F. Biomechanics, 7, I I-I 9.

Uhthoff, H. K. (1974). Calcifying tendinitis vs rotator cuff ruptures. Canadian Orthopaedic Association 3oth Annual Meeting. St. John's, Newfoundland.

WIENER, D. S. \& MACNAB, I. (1970). Superior migration of the humeral head. F. Bone and foint Surgery, 52B, 524-527.

Wright, V. \& HAQ, M. M. M. (I976). Periarthritis of the shoulder. Ann. Rheum. Dis., 35, 213-2 I9. 